\title{
The epidemiology of childhood asthma in Red Deer and Medicine Hat, Alberta
}

\author{
Patrick A Hessel PhD ${ }^{1}$, Justine Klaver BSc BA ${ }^{1}$, Dennis Michaelchuk BEd MA ${ }^{1}$, \\ Shawna McGhan RN MN CAE ${ }^{2}$, Mary M Carson $\mathrm{PhD}^{3}$, Darrel Melvin RRT ${ }^{4}$ \\ ${ }^{1}$ Department of Public Health Sciences, University of Alberta; ${ }^{2}$ Alberta Asthma Centre; \\ ${ }^{3}$ Alberta Lung Association, Edmonton; ${ }^{4}$ Community Respiratory Services, \\ Red Deer Regional Hospital, Red Deer, Alberta
}

PA Hessel, J Klaver, D Michaelchuk, S McGhan, MM Carson, D Melvin. The epidemiology of childhood asthma in Red Deer and Medicine Hat, Alberta. Can Respir J 2001;8(3):139-146.

OBJECTIVES: To document the prevalence of asthma among school-aged children in two Alberta communities, to understand host and indoor environmental factors associated with asthma, and to compare these factors between the two communities.

DESIGN: A cross-sectional study with a nested, case-control follow-up.

SETTING: Red Deer and Medicine Hat, Alberta.

PATIENTS AND METHODS: Questionnaires were sent to families of children aged five to 19 years in Red Deer $(\mathrm{n}=5292)$ and Medicine Hat $(\mathrm{n}=5372)$ to identify children with current asthma. A random sample of 592 children with current asthma and 443 with no history of asthma constituted a case-control population; they were followed up by telephone to obtain responses to the European Respiratory Health Survey and, in children with current asthma, the Pediatric Quality of Life Questionnaire.

RESULTS: Cross-sectional response rates were $84 \%$ and 73\% for Red Deer and Medicine Hat, respectively. The prevalence of asthma was higher in Medicine Hat (17.0\%) than in Red Deer (12.8\%). In the follow-up study, factors associated with the presence of asthma were parental asthma or allergies, number of siblings, presence of cats, serious respiratory illnesses before five years of age, sex, age, presence of mould and/or mildew and use of a gas cooking stove. The pres- ence of mould and/or mildew was a significant risk factor in Red Deer but not in Medicine Hat.

CONCLUSIONS: Asthma prevalence among school children in Red Deer was consistent with recently published Canadian data; the prevalence in Medicine Hat was higher than expected, especially given the low relative humidity. Risk factor data are consistent with other studies in that parental asthma, especially maternal asthma, was a significant predictor of childhood asthma. Cats in the house (both communities) and environmental tobacco smoke (Medicine Hat only) were significantly less common among children with asthma, suggesting that preventive actions may have been taken in the homes of some children with asthma.

Key Words: Childhood asthma; Family history; Indoor environment; Prevalence

\section{Épidémiologie de l'asthme infantile à Red} Deer et à Medicine Hat en Alberta

OBJECTIFS : Documenter la prévalence de l'asthme chez les enfants d'âge scolaire de deux communautés albertaines pour comprendre les facteurs liés à l'hôte et les facteurs liés à l'environnement associés à l'asthme et comparer ces facteurs entre les deux communautés.

MODÈLE : Étude transversale de suivi avec cas/témoins emboîtés. CONTEXTE : Red Deer et Medicine Hat, Alberta.

PATIENTS ET MÉTHODES : Des questionnaires ont été envoyés aux familles d'enfants de 5 à 19 ans de Red Deer $(n=5$ 292)

voir page suivante 
et de Medicine Hat ( $n=5372)$ afin d'identifier les enfants actuellement atteints d'asthme. Un échantillon aléatoire de 592 enfants atteints d'asthme et de 443 sujets sans antécédents d'asthme a constitué la population cas/témoins. Ils ont été suivis par téléphone au moyen du European Respiratory Health Survey et, chez les enfants souffrant d'asthme, au moyen du Pediatric Quality of Life Questionnaire.

RÉSULTATS : Les taux de réponse ont été de 84 et de $73 \%$ pour Red Deer et Medicine Hat, respectivement. La prévalence de l'asthme a été plus forte à Medicine Hat $(17,0 \%)$ qu'à Red Deer $(12,8 \%)$. Lors de l'étude de suivi, les facteurs associés à la présence de l'asthme ont été l'asthme ou les allergies parentaux, le nombre de frères et sœurs, la présence de chats, les maladies respiratoires graves avant l'âge de cinq ans, le sexe, l'âge, la présence de moisissures et l'utilisation d'une cuisinière au gaz. La présence de moisis- sures s'est révélée être un facteur de risque significatif à Red Deer, mais non à Medicine Hat.

CONCLUSIONS : La prévalence de l'asthme chez les enfants d'âge scolaire à Red Deer concordait avec les statistiques canadiennes publiées récemment. À Medicine Hat, elle s'est révélée plus élevée que prévue, surtout compte tenu de la faible humidité relative. Les données sur les facteurs de risque concordaient avec d'autres études en ce sens que l'asthme parental, surtout l'asthme maternel, était un important facteur de prévisibilité de l'asthme infantile. La présence de chats dans la maison (dans les deux communautés) et le tabagisme (à Medicine Hat, seulement) ont été beaucoup moins communs chez les enfants asthmatiques, ce qui donne à penser que des mesures préventives peuvent avoir été prises dans les foyers de certains enfants asthmatiques.
A sthma is a common, chronic condition in Canada with an estimated 1.5 million or more persons affected (1). Of these, at least half a million are between birth and 19 years of age. A number of Canadian and international studies have documented increases in the prevalence of asthma (2-4), in hospital admissions due to asthma (5-7) and in asthmarelated mortality $(5,8-10)$. Several studies have indicated that although hospitalizations due to asthma are increasing in all age groups and for both sexes, children are experiencing the greatest increases (5-7).

Asthma is multifactorial in nature, and has been linked with environmental and host factors. Some studies have shown that persons with a genetic predisposition to asthma are more likely to develop the disease when exposed to environmental allergens (11). Host factors include age, sex, history of personal allergies, and diagnosed allergies or asthma in a biological parent (12). In industrialized countries, especially those with cold climates, people spend the majority of their time indoors (13). Furthermore, modern home construction produces indoor climates that favour the growth of certain allergens (house dust mite, and mould and/or mildew) (14). Indoor environmental factors potentially related to asthma include environmental tobacco smoke, home dampness or water damage, mould and/or mildew, and pets (12).

This study had three goals: to document the prevalence of asthma among school-aged children in Medicine Hat and Red Deer, Alberta; to understand the host and indoor environmental risk factors associated with the presence of childhood asthma in these cities; and to compare environmental risk factors and asthma triggers associated with asthma between the two communities.

\section{PATIENTS AND METHODS}

An initial screening questionnaire was distributed to students in 16 schools in Red Deer (central Alberta) and in 20 schools in Medicine Hat (southern Alberta). The numbers of high schools (grades 10 to 12), junior high schools (grades 7 to 9) and elementary schools (kindergarten to grade 6) were chosen so that the proportion of respondents in each stratum approximated the proportion within the total student population for each city. Schools in each category were selected randomly from lists of Catholic, public and private schools.

The questionnaires were distributed to the students, and completed by parents or guardians, except at one high school in each community where the students completed the questionnaires at school. Current asthma was defined as positive responses to each of the following three questions: Has your child ever had asthma? Was the asthma confirmed by a doctor? Does your child still have asthma? This definition was based on a previous Canadian study (12).

All respondents to the screening questionnaire were asked for permission to perform a follow-up interview. Follow-up interviews were conducted by telephone with the parents or guardians of a random sample of 1198 students who completed the screening questionnaire and had agreed to participate in the follow-up. Of these, 592 met the criteria for asthma from the screening questionnaire and had an 'attack' of asthma within the past year, or were taking asthma medication. These participants were classified as having asthma for the case-control study. There were 443 participants who had no history of asthma (classified as controls for the case-control study). There were 119 participants who had asthma according to the screening questionnaire but were not taking medication for asthma and did not have an attack in the past year. Forty-four participants had missing or inconsistent information. For the purposes of this study, only students with asthma according to the telephone interview criteria (cases) or with no history of asthma (controls) were included in the analysis $(n=1035)$.

The telephone survey was based on the European Community Respiratory Health Survey (15) and included questions about demographic, environmental, medical history and host factors (including parental asthma and allergies). For patients with asthma, the Paediatric Asthma Quality of Life Questionnaire (16) and the SF-12 Health Survey (17) were included. The present analysis focused on the host and indoor environmental factors.

Bivariate analyses were conducted using the ${ }^{2}$ test, and by calculating odds ratios (ORs) and 95\% CIs. Potentially confounding factors were assessed using unconditional logistic regression techniques. A backward elimination procedure was used. Variables significantly related to a person's status 
TABLE 1

Prevalence of asthma by age and sex for children in Red Deer and Medicine Hat, Alberta, and in both communities combined

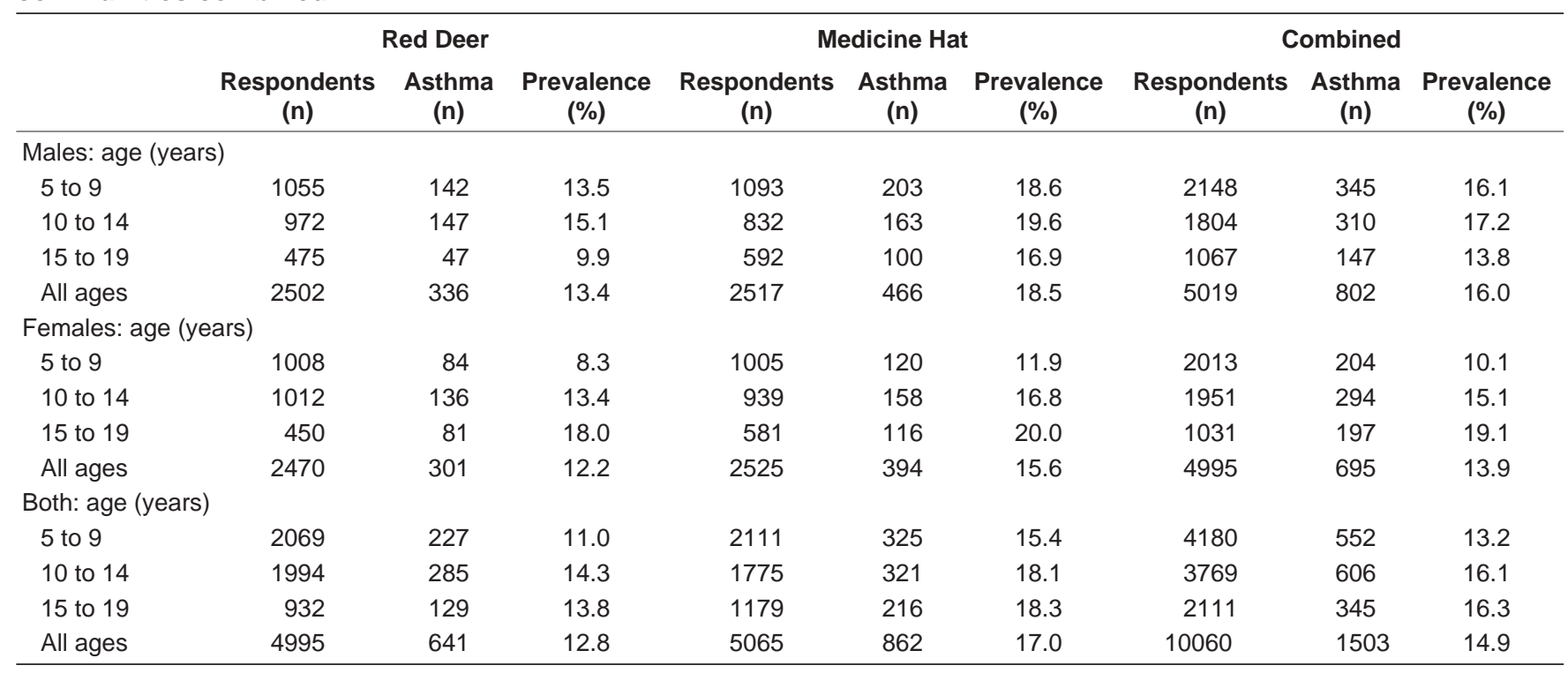

TABLE 2

Description of the respondents in the case-control follow-up examining the host and indoor environmental factors associated with asthma in Red Deer and Medicine Hat, Alberta

\begin{tabular}{|c|c|c|c|c|c|c|}
\hline & \multicolumn{2}{|c|}{ Red Deer } & \multicolumn{2}{|c|}{ Medicine Hat } & \multicolumn{2}{|c|}{ Combined } \\
\hline & Asthma (n [\%]) & Controls (n [\%]) & Asthma (n [\%]) & Controls (n [\%]) & Asthma (n [\%]) & Controls (n [\%]) \\
\hline \multicolumn{7}{|c|}{ Males: age (years) } \\
\hline 5 to 9 & $78(45.3)$ & $50(49.0)$ & $81(48.5)$ & $46(43.4)$ & $159(46.9)$ & $96(46.2)$ \\
\hline 10 to 14 & $75(43.6)$ & $39(38.2)$ & $61(36.5)$ & $40(37.7)$ & $136(40.1)$ & $79(38.0)$ \\
\hline 15 to 19 & $19(11.0)$ & $13(12.7)$ & $25(15.0)$ & 20 (18.9) & $44(13.0)$ & 33 (15.9) \\
\hline Total & $172(100)$ & $102(100)$ & $167(100)$ & $106(100)$ & $339(100)$ & $208(100)$ \\
\hline \multicolumn{7}{|c|}{ Females: age (years) } \\
\hline 5 to 9 & $37(30.3)$ & $39(31.7)$ & $36(27.5)$ & $44(39.3)$ & 73 (28.9) & $83(35.3)$ \\
\hline 10 to 14 & $59(48.4)$ & $65(52.8)$ & $62(47.3)$ & $41(36.6)$ & $121(47.8)$ & $106(45.1)$ \\
\hline 15 to 19 & $26(21.3)$ & 19 (15.4) & 33 (25.2) & $27(24.1)$ & 59 (23.3) & 46 (19.6) \\
\hline Total & 112 (100) & 123 (100) & $131(100)$ & 112 (100) & 253 (100) & 235 (100) \\
\hline
\end{tabular}

as a case or control that might have been part of the disease process (eg, history of pneumonia or bronchitis) were not entered into the multivariate model. Differences in the associations between asthma and risk factors between the communities were tested by using the final regression model for the two communities combined, adding an indicator variable for 'community' and an interaction term for each variable with the 'community' variable (ie, both main effects were included, as well as the interaction term). Each interaction was evaluated in a separate model.

Ethics approval was obtained from the Health Ethics Review Board at the University of Alberta, Edmonton, Alberta.

\section{RESULTS}

Cross-sectional study: Response rates for the cross-sectional study were $84 \%$ in Red Deer and $73 \%$ in Medicine Hat. The prevalence of current asthma among students included in the initial screening survey was $12.8 \%$ in Red Deer and $17.0 \%$ in Medicine Hat (Table 1). The prevalence was highest for females aged 15 to 19 years in Medicine Hat $(20.0 \%)$ and lowest for females aged 5 to 9 years in Red Deer $(8.3 \%)$. The prevalence for children younger than 15 years of age was higher in boys; however, girls had a higher prevalence in the 15- to 19-year-old age group.

Case-control study: Approximately two-thirds (65\%) of the respondents to the screening survey agreed to be contacted for the follow-up survey. Of those who were contacted for follow-up, 97\% completed the interview. Asthma was more common among male than female respondents (Table 2). Male sex was a significant risk factor in Red Deer (OR 1.7, 95\% CI 1.2 to 2.4) and for both communities combined (OR 1.5, 95\% CI 1.2 to 1.9). Positive histories of allergies and respiratory conditions were significantly more common among case subjects than among control subjects in 
TABLE 3

Comparison of host factors for asthma cases and controls in the follow-up study

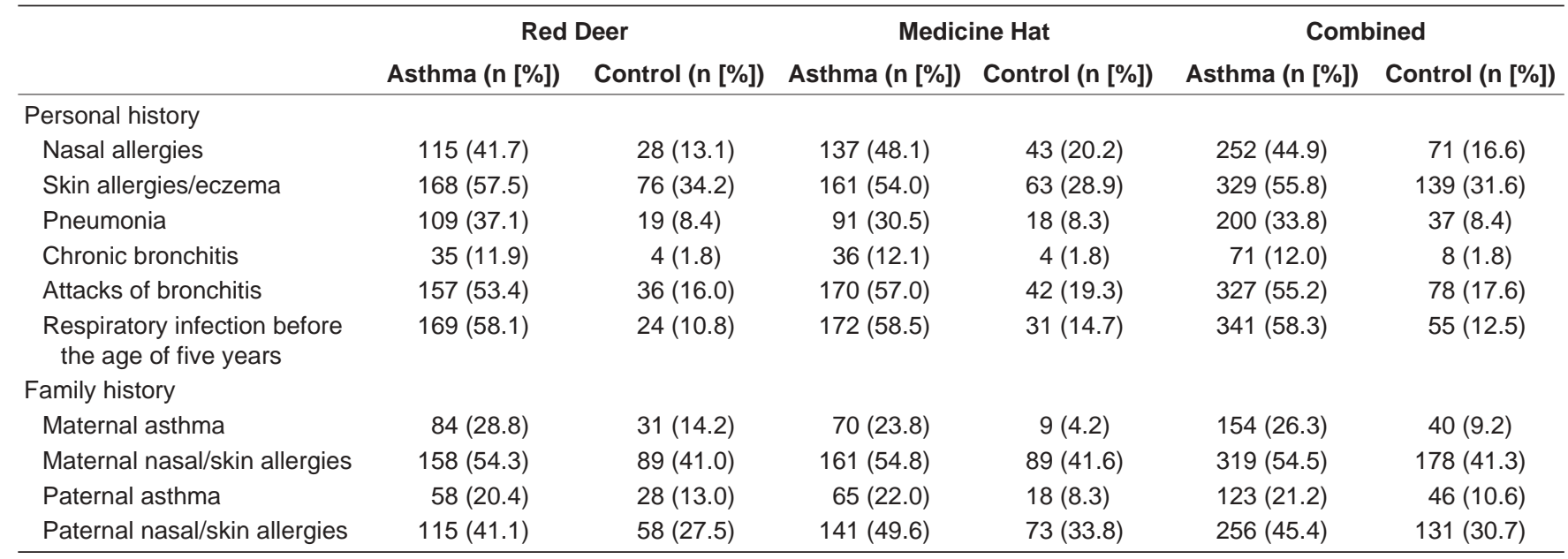

TABLE 4

Odds ratios (ORs) and $95 \%$ Cls for selected environmental factors in relation to asthma in the follow-up study

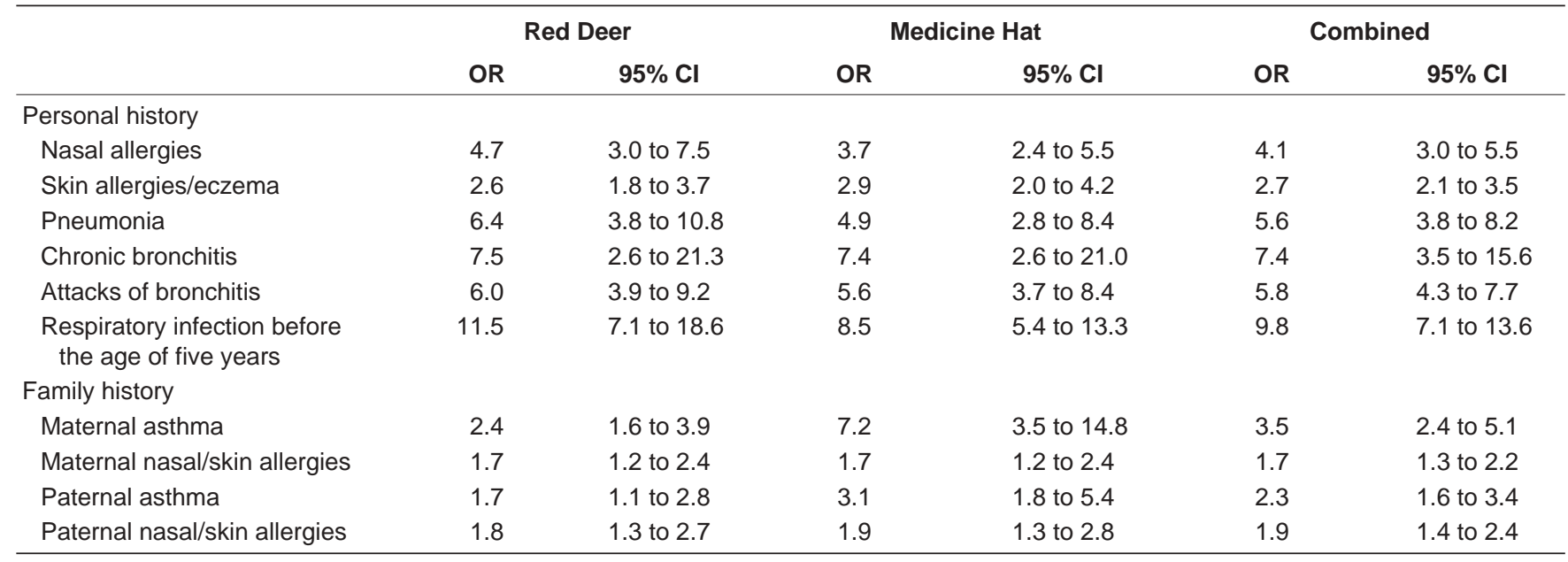

both communities (Table 3). Case subjects were also more likely than controls to have a maternal or paternal history of asthma and allergies. ORs for personal history variables varied from 9.8 (95\% CI 7.1 to 13.6) for a history of a serious respiratory infection before the age of five years to 2.7 (95\% CI 2.1 to 3.5) for a history of skin allergies or eczema (Table 4). Maternal asthma was the family history variable most strongly associated with childhood asthma. The OR for maternal asthma was higher in Medicine Hat than in Red Deer.

Although personal smoking was less common in children with asthma than in control subjects, exposure to passive smoke did not differ overall or in Red Deer (Tables 5 and 6); however, children with asthma in Medicine Hat were marginally less likely than control subjects to be exposed to passive smoke. Children with asthma (especially in Red Deer) were more likely to have a gas stove in the home. Cats were less common in the homes of children with asthma.
The case-control difference was more pronounced in Medicine Hat. Children with asthma were more likely to have mould and/or mildew in the home in the past year, especially those in Red Deer. The presence of asthma was not associated with water damage or the age of the house. Children with asthma were more likely than control subjects to have no siblings. The difference was most prominent when comparing the proportions of cases and controls with four or more siblings (versus none) $(\mathrm{OR}=0.4 ; 95 \% \mathrm{CI} 0.2$ to 0.9 ). Other environmental factors investigated (but not presented) were parental smoking during childhood, home appliances used for cooking other than the stove, years in the home, type of home, type of home heating, and furry pets other than cats or dogs. None of these were associated with the presence of asthma.

Variables significantly related to asthma in the bivariate analysis were examined in a multivariate logistical regression analysis (Table 7). The personal history variables listed 
TABLE 5

Comparison of selected environmental factors for patients with asthma and control subjects in Red Deer and Medicine Hat, Alberta

\begin{tabular}{|c|c|c|c|c|c|c|}
\hline \multirow[b]{2}{*}{ Risk factor } & \multicolumn{2}{|c|}{ Red Deer } & \multicolumn{2}{|c|}{ Medicine Hat } & \multicolumn{2}{|c|}{ Combined } \\
\hline & Asthma (n [\%]) & Controls (n [\%]) & Asthma (n [\%]) & Controls (n [\%]) & Asthma (n [\%]) & Controls (n [\%]) \\
\hline Ever smoked & $7(2.4)$ & $13(5.8)$ & $9(3.0)$ & $15(6.7)$ & $16(2.7)$ & $28(6.3)$ \\
\hline Smoker in home & $71(24.2)$ & $51(22.8)$ & $32(20.9)$ & $60(27.5)$ & $133(22.5)$ & $111(25.1)$ \\
\hline $\begin{array}{l}\text { Regular exposure to } \\
\text { passive smoke } \\
\text { (past year) }\end{array}$ & $86(29.3)$ & $55(24.6)$ & $79(26.6)$ & $74(33.9)$ & $165(27.9)$ & $129(29.2)$ \\
\hline Cat in house & $58(19.6)$ & $57(25.6)$ & $60(20.2)$ & $69(31.7)$ & $118(20.0)$ & $126(28.6)$ \\
\hline $\begin{array}{l}\text { Mould and/or mildew } \\
\text { in home (past year) }\end{array}$ & $69(23.5)$ & $29(13.2)$ & $50(16.9)$ & $34(15.7)$ & $119(20.3)$ & $63(14.4)$ \\
\hline $\begin{array}{l}\text { Water damage } \\
\text { (past year) }\end{array}$ & $44(15.4)$ & $27(12.2)$ & $40(13.7)$ & $34(15.6)$ & $84(14.5)$ & $61(13.9)$ \\
\hline One & $145(49.5)$ & $106(47.3)$ & $119(39.9)$ & 105 (48.2) & $264(44.7)$ & $211(47.7)$ \\
\hline Two & $90(30.7)$ & $62(27.7)$ & $95(31.9)$ & $66(30.3)$ & $185(31.3)$ & $128(29.0)$ \\
\hline Three & $27(9.2)$ & $19(8.5)$ & $37(12.4)$ & $19(8.7)$ & $64(10.8)$ & $38(8.6)$ \\
\hline Four or more & $6(2.0)$ & $18(8.0)$ & $18(6.0)$ & $15(6.9)$ & $24(4.1)$ & $33(7.5)$ \\
\hline
\end{tabular}

TABLE 6

Odds ratios (ORs) and $95 \%$ Cls for selected environmental factors in relation to asthma in children from Red Deer and Medicine Hat, Alberta

\begin{tabular}{|c|c|c|c|c|c|c|}
\hline \multirow[b]{2}{*}{ Risk factor } & \multicolumn{2}{|c|}{ Red Deer } & \multicolumn{2}{|c|}{ Medicine Hat } & \multicolumn{2}{|c|}{ Combined } \\
\hline & OR & $95 \% \mathrm{Cl}$ & OR & $95 \% \mathrm{Cl}$ & OR & $95 \% \mathrm{Cl}$ \\
\hline Ever smoked & 0.4 & 0.2 to 1.0 & 0.4 & 0.1 to 1.0 & 0.4 & 0.2 to 0.8 \\
\hline Current smoker & 0.4 & 0.1 to 1.3 & 0.5 & 0.2 to 1.2 & 0.4 & 0.2 to 0.9 \\
\hline Smoker in home & 1.1 & 0.7 to 1.6 & 0.7 & 0.5 to 1.0 & 0.9 & 0.7 to 1.2 \\
\hline $\begin{array}{l}\text { Regular exposure to passive smoke } \\
\text { (past year) }\end{array}$ & 1.3 & 0.9 to 1.9 & 0.7 & 0.5 to 1.0 & 0.9 & 0.7 to 1.2 \\
\hline Gas cooking & 2.2 & 1.1 to 4.3 & 1.2 & 0.5 to 2.6 & 1.6 & 1.0 to 2.8 \\
\hline Cat in house & 0.7 & 0.5 to 1.1 & 0.5 & 0.4 to 0.8 & 0.6 & 0.5 to 0.8 \\
\hline Mould and/or mildew in home (past year) & 2.1 & 1.3 to 3.3 & 1.1 & 0.7 to 1.8 & 1.5 & 1.1 to 2.1 \\
\hline Water damage (past year) & 1.3 & 0.8 to 2.2 & 0.9 & 0.5 to 1.4 & 1.1 & 0.7 to 1.5 \\
\hline Age of home (less than 20 years) & 0.8 & 0.6 to 1.2 & 1.3 & 0.9 to 1.8 & 1.0 & 0.8 to 1.3 \\
\hline \multicolumn{7}{|l|}{ Number of siblings } \\
\hline One versus none & 1.0 & 0.5 to 2.0 & 0.5 & 0.3 to 1.0 & 0.7 & 0.5 to 1.2 \\
\hline Two versus none & 1.1 & 0.6 to 2.2 & 0.6 & 0.3 to 1.3 & 0.9 & 0.5 to 1.4 \\
\hline Three versus none & 1.1 & 0.5 to 2.5 & 0.9 & 0.4 to 2.1 & 1.0 & 0.6 to 1.8 \\
\hline Four or more versus none & 0.3 & 0.1 to 0.8 & 0.5 & 0.2 to 1.4 & 0.4 & 0.2 to 0.9 \\
\hline
\end{tabular}

in Tables 3 and 4 were not included in this analysis. Variables such as personal smoking and presence of cats in the home were also excluded. Although these are known risk factors for asthma, some individuals may have reduced their exposures to these triggers as a result of having asthma. The analysis suggested that male sex, gas cooking, exposure to mould or mildew in the past year, maternal and paternal asthma and allergies, and the number of siblings (especially four siblings versus none) were significantly associated with asthma. Gas cooking and maternal allergies were only marginally significant in this analysis. In Red Deer, male sex, exposure to mould or mildew in the past year, maternal asthma, paternal allergies and/or eczema, and number of siblings were significantly associated with asthma. In Medicine Hat, family histories of asthma and allergies were the only factors associated with asthma in addition to age and sex. Maternal asthma remained the most significant factor in both cities. 
TABLE 7

Multivariate odds ratios (ORs) and $95 \%$ Cls for risk factors in relation to asthma in children from Red Deer and Medicine Hat, Alberta

\begin{tabular}{|c|c|c|c|c|c|c|}
\hline \multirow[b]{2}{*}{ Variable } & \multicolumn{2}{|c|}{ Red Deer } & \multicolumn{2}{|c|}{ Medicine Hat } & \multicolumn{2}{|c|}{ Combined } \\
\hline & OR & $95 \% \mathrm{Cl}$ & OR & $95 \% \mathrm{Cl}$ & OR & $95 \% \mathrm{Cl}$ \\
\hline Sex & 1.6 & 1.1 to 2.4 & 1.4 & 0.9 to 2.0 & 1.5 & 1.1 to 2.0 \\
\hline Gas cooking & 2.0 & 0.9 to 4.2 & - & - & 1.7 & 1.0 to 3.1 \\
\hline Mould and/or mildew exposure in the past year & 2.4 & 1.4 to 4.0 & - & - & 1.6 & 1.1 to 2.3 \\
\hline Age & - & - & 1.0 & 1.0 to 1.1 & - & - \\
\hline Maternal asthma & 2.4 & 1.5 to 4.0 & 6.2 & 2.9 to 13.1 & 3.1 & 2.0 to 4.7 \\
\hline Maternal nasal or skin allergies/eczema & - & - & 1.4 & 1.0 to 2.1 & 1.3 & 1.0 to 1.8 \\
\hline Paternal asthma & - & - & 2.9 & 1.6 to 5.3 & 2.0 & 1.3 to 3.0 \\
\hline Paternal nasal or skin allergies/eczema & 1.8 & 1.2 to 2.8 & 1.5 & 1.0 to 2.3 & 1.7 & 1.2 to 2.2 \\
\hline \multicolumn{7}{|l|}{ Number of siblings } \\
\hline One versus none & 1.4 & 0.7 to 3.0 & - & - & 0.9 & 0.5 to 1.5 \\
\hline Two versus none & 1.3 & 0.6 to 2.9 & - & - & 0.8 & 0.5 to 1.5 \\
\hline Three versus none & 1.4 & 0.5 to 3.6 & - & - & 1.1 & 0.6 to 2.1 \\
\hline Four or more versus none & 0.4 & 0.1 to 1.2 & - & - & 0.4 & 0.2 to 0.8 \\
\hline
\end{tabular}

TABLE 8

\section{Comparison of the percentage of children with asthma reporting specific asthma triggers between two communities in Alberta}

\begin{tabular}{lcccc}
\hline Trigger & $\begin{array}{c}\text { Red Deer } \\
(\mathbf{n}=\mathbf{2 9 4})\end{array}$ & $\begin{array}{c}\text { Medicine Hat } \\
(\mathbf{n}=\mathbf{2 9 8})\end{array}$ & $\begin{array}{c}\text { Combined } \\
(\mathbf{n}=592)\end{array}$ & $\mathbf{P}$ \\
\hline Pollens & 54.8 & 52.0 & 53.4 & 0.56 \\
Moulds & 56.5 & 35.9 & 46.1 & $<0.001$ \\
House dust & 45.2 & 40.3 & 42.7 & 0.26 \\
Other dusts & 50.3 & 52.7 & 51.5 & 0.62 \\
Colds, influenza & 85.7 & 86.6 & 86.1 & 0.85 \\
Physical activity & 62.2 & 67.4 & 64.9 & 0.22 \\
Stress & 30.6 & 28.5 & 29.6 & 0.64 \\
Excitement & 28.9 & 30.5 & 29.7 & 0.73 \\
Depression & 6.1 & 4.4 & 5.2 & 0.44 \\
Burning field & 36.1 & 23.2 & 29.6 & 0.001 \\
$\quad$ stubble & & & & \\
Cold air & 52.4 & 54.7 & 53.5 & 0.63 \\
Weather changes & 48.0 & 51.7 & 49.8 & 0.41 \\
Cats & 46.9 & 45.0 & 45.9 & 0.69 \\
Dogs & 30.6 & 28.5 & 29.6 & 0.64 \\
Horses & 28.2 & 22.1 & 25.2 & 0.11 \\
Other animals & 22.8 & 16.4 & 19.6 & 0.07 \\
Foods & 17.7 & 11.4 & 14.5 & 0.04 \\
Drugs & 6.1 & 5.4 & 5.7 & 0.83 \\
Cigarette smoke & 66.0 & 64.8 & 65.4 & 0.82 \\
Wood smoke & 46.6 & 38.9 & 42.7 & 0.07 \\
Perfume & 25.9 & 19.1 & 22.5 & 0.06 \\
Air pollution & 29.9 & 19.5 & 24.7 & 0.004 \\
\hline
\end{tabular}

When interaction terms were added to the final model for both communities (from Table 7) to compare risk factors between the communities, the interaction terms for mould or mildew exposure and maternal asthma were significant $(\mathrm{P}=0.04$ and $\mathrm{P}=0.01$, respectively).

The comparison of asthma triggers for children with asthma in the two communities showed that the most common trigger was colds or influenza $(86 \%)$, followed by exposure to cigarette smoke $(65 \%)$ and physical activity $(65 \%)$ (Table 8$)$. The triggers with the largest differences between the communities were airborne allergen exposures, specifically moulds, burning field stubble and air pollution; all were more commonly cited as triggers in Red Deer.

\section{DISCUSSION}

The cross-sectional study had the advantage of drawing from a large population of children with good response rates so that prevalence estimates were reliable. Similarly, the case-control follow-up had sufficient power to detect ORs of approximately 1.5 or greater.

The study was limited by the use of self-reports of asthma, symptoms, and personal and family history. Although selfreports are typical in these studies, measurements of lung function and/or bronchial responsiveness would have been helpful in verifying or at least supplementing the reports.

The use of two different criteria for asthma - one in the cross-sectional study and the other in the case-control follow-up - showed the problems associated with defining asthma in epidemiological studies. There were 711 respondents to the case-control follow-up who were classified in the cross-sectional study as having asthma. Of these, 119 children $(16.7 \%)$ did not meet the criteria for asthma in the case-control follow-up (ie, they had not had an 'attack' within the past year and were not taking asthma medications). These 119 children were excluded from the casecontrol analysis. The characteristics of this group and their impact on prevalence estimates are being explored (18).

A study conducted by Health Canada examined asthma prevalence in children aged five to 19 years in nine health units across the country (1). The overall prevalence was $12.9 \%$. The figure for Edmonton, Alberta (one of the participating health units), was also $12.9 \%$. This prevalence estimate was comparable with that documented in the present study for Red Deer (12.8\%) but lower than the estimate for 
Medicine Hat (17.0\%). The definition of asthma in the Health Canada study was similar to the definition used in the present case-control follow-up. Health Canada defined asthma in children as a physician's diagnosis of asthma and the presence of least one of the following three criteria in the past 12 months: an attack of asthma, use of asthma medications, or wheeze or whistling in the chest (1). In the present study, only one-quarter of the 119 children who met the criteria for asthma in the cross-sectional study - but not in the casecontrol study - had wheezed within the past year.

Three Canadian studies have estimated asthma prevalence using administrative health data. The prevalence of asthma in children in Saskatchewan was estimated at 5.1\% for those under five years of age and $4.4 \%$ in the five- to 14 -year-old age group (3). The prevalence of asthma in Manitoba children ranged from $2.8 \%$ to $4.4 \%$ for various childhood age groups (4). On the basis of at least one contact with the health care system coded for asthma during a five-year period, asthma prevalence for children in Alberta from birth to nine years of age was approximately $12 \%$ and $8 \%$ for males and females, respectively (19). The figures for those aged 10 to 19 years were approximately $5.5 \%$ for both males and females. When based on at least three contacts with the health care system coded for asthma during the five-year period, the prevalence estimates for males and females from birth to nine years of age were $5 \%$ and $3 \%$, respectively, and $2 \%$ for males and females aged 10 to 19 years. These estimates would be expected to be low (compared with population surveys) given that some patients may not contact the health care system regularly for asthma and some contacts with the health care system may be coded to another rubric (4).

The patterns of prevalence by age and sex were similar to those found in other studies - asthma was more common among young males and there was a female predominance after puberty $(3,4,19,20)$. The reasons for the higher prevalence in Medicine Hat than in Red Deer are not readily apparent. Outdoor humidity is lower in Medicine Hat, suggesting that asthma prevalence should be lower $(12,21)$. None of the indoor environmental risk factors was significantly associated with asthma in Medicine Hat. O'Hollaren et al (22) found that, among children younger than 17 years of age, sensitivity to Alternaria species was more common among those with asthma than those without asthma. They noted that Alternaria species reached high concentrations in the graingrowing areas of the mid-western United States. Medicine Hat is an area of intense grain farming, whereas the area around Red Deer is characterized by mixed farming and industrial activities. All of the schools, however, were within city limits in both communities. A comparison of immediate skin sensitivity to Alternaria species and/or an examination of specific immunoglobulin $\mathrm{E}$ would be required to determine whether Alternaria species or other airborne allergens may account for the relatively high prevalence of asthma in Medicine Hat. A comparison of the diagnostic habits of physicians in the two communities may also provide useful insights.

The host factors found to be associated with asthma in the present study were comparable with those shown in other studies. Associations with maternal and/or paternal asthma and allergies (23-25), a history of nasal allergies or eczema $(21,25)$, and a history of a serious respiratory infection before five years of age (26) have previously been found. As in most other studies, maternal asthma appeared to be more predictive of asthma than paternal asthma (25). Although maternal asthma was significantly associated with asthma in both communities, the relationship in Medicine Hat was stronger, as indicated by the significant interaction term.

Of the indoor environmental factors examined, only mould or mildew in the home and gas cooking were significantly associated with asthma. In both instances, the relation was stronger for Red Deer than for Medicine Hat. Both of these factors have been shown to be associated with asthma in previous studies $(20,27)$. The significant interaction between 'community' and exposure to mould or mildew suggested a stronger relationship in Red Deer than in Medicine Hat. In fact, none of the environmental variables was significantly related to asthma in Medicine Hat, while the ORs for family history variables were generally higher in Medicine Hat than in Red Deer (significantly higher for maternal asthma). The comparison of asthma triggers for children with asthma in the two communities also showed that environmental allergens triggered asthma more commonly in Red Deer, while most nonallergen triggers (eg, colds, physical activity) did not differ between communities.

Children with siblings were less likely to have asthma than children without siblings. The relation was strongest for those with four or more siblings. It has been suggested that early exposure to respiratory infections inhibits the development of atopy and that the presence of siblings may increase opportunities for respiratory infections $(28,29)$. Wickens et al (30) also found an association between smaller family size and risk of asthma.

The results of the present study differed from those of several others $(20,31,32)$ in that environmental tobacco smoke was not associated with asthma. This may have been the result of increased societal awareness about asthma and its triggers, and actions on the part of parents and caregivers to limit exposures for children with asthma. Similarly, there was a negative association between asthma and the presence of cats in the house. Because cats are a known, common trigger of asthma, this result suggests that exposures had been intentionally limited. While this is encouraging, it should be noted that among children with asthma, $22.5 \%$ had a smoker in the home, $27.9 \%$ were regularly exposed to passive tobacco smoke and $20.0 \%$ had a cat in the house. This speaks to the continued need to inform children with asthma, caregivers and others responsible for the environments of children about the importance of limiting potentially harmful exposures.

ACKNOWLEDGEMENTS: The study was funded by the Alberta Heritage Foundation for Medical Research, the Alberta Lung Association, AstraZeneca Inc, Aventis, Merck Frosst Canada Inc and the Clinical Practice Guidelines Program of the Alberta Medical Association. 


\section{REFERENCES}

1. Health Canada. Childhood Asthma in Sentinel Health Units: Report of the Student Lung Health Survey Results 1995-1996 [Catalogue No H49-120/1998E]. Ottawa: Health Canada, 1998.

2. Vollmer WM, Osborne ML, Buist AS. 20-year trends in the prevalence of asthma and chronic airflow obstruction in an HMO. Am J Respir Crit Care Med 1998;157:1079-84.

3. Senthilselvan A. Prevalence of physician-diagnosed asthma in Saskatchewan, 1981 to 1990. Chest 1998;114:388-92.

4. Manfreda J, Becker AB, Wang P-Z, Roos LL, Anthonisen NR. Trends in physician-diagnosed asthma prevalence in Manitoba between 1980 and 1990. Chest 1993;103:151-7.

5. Mannino DM, Homa DM, Pertowski CA, et al. Surveillance for asthma - United States, 1960-1995. Morb Mortal Wkly Rep CDC Surveill Summ 1998;47:1-27.

6. Gergen PJ, Weiss KB. Changing patterns of asthma hospitalization among children: 1979 to 1987. JAMA 1990;264:1688-92.

7. Wilkins K, Mao Y. Trends in rates of admission to hospital and death from asthma among children and young adults in Canada during the 1980s. CMAJ 1993;148:185-90.

8. FitzGerald JM, Macklem P. Fatal asthma. Annu Rev Med 1996;47:161-8

9. McFadden ER Jr, Warren EL. Observations on asthma mortality. Ann Intern Med 1997;127:142-7.

10. Weiss KB, Wagener DK. Changing patterns of asthma mortality: Identifying target populations at high risk. JAMA 1990;264:1683-7.

11. Squillace SP, Sporik RB, Rakes G, et al. Sensitization to dust mites as a dominant risk factor for asthma among adolescents living in central Virginia: Multiple regression analysis of a population-based study. Am J Respir Crit Care Med 1997;156:1760-4

12. Dales RE, Raizenne M, el-Saadany S, Brook J, Burnett R Prevalence of childhood asthma across Canada. Int J Epidemiol 1994;23:775-81

13. Samet JM, Marbury MC, Spengler JD. Health effects and sources of indoor air pollution. Part 1. Am Rev Respir Dis 1987;136:1486-508.

14. Munir AKM, Björkstén B, Einarsson R, et al. Mite allergens in relation to home conditions and sensitization of asthmatic children from three climatic regions. Allergy 1995;50:55-64.

15. Burney PGJ, Luczynska C, Chinn S, Jarvis D. The European Community Respiratory Health Survey. Eur Respir J 1994;7:954-60.

16. Juniper EF, Guyatt GH, Ferrie PJ, Griffith LE. Measuring quality of life in asthma. Am Rev Respir Dis 1993;147:832-8.

17. Ware JE, Kosinski M, Keller SD. SF-12: How to Score the SF-12 Physical and Mental Health Summary Scales. Boston: The Health Institute, New England Medical Center, 1995.
18. Hessel PA, Michaelchuk D, Klaver J, McGhan S, Carson MM, Drixler C. The effect of varying definitions on estimates of asthma prevalence. Am J Respir Crit Care Med 2000;161:A794. (Abst)

19. Svenson LW, Woodhead SE, Platt GH. Estimating the prevalence of asthma in Alberta: A study using provincial health care records. Chron Dis Canada 1993;14:28-33.

20. Dekker C, Dales R, Bartlett S, Brunekreef B, Zwanenburg H. Childhood asthma and the indoor environment. Chest 1991;100:922-6.

21. Smedje G, Norbäck D, Edling C. Asthma among secondary schoolchildren in relation to the school environment. Clin Exp Allergy 1997;27:1270-8.

22. O'Hollaren MT, Yunginger JW, Offord KP, et al. Exposure to an aeroallergen as a possible precipitating factor in respiratory arrest in young patients with asthma. N Engl J Med 1991;324:359-63.

23. Slezak JA, Persky VW, Kviz FJ, Ramakrishnan V, Byers C. Asthma prevalence and risk factors in selected Head Start sites in Chicago. J Asthma 1998;35:203-12.

24. Ronmark E, Lundback B, Jonsson E, Platts-Mills T. Asthma, type-1 allergy and related conditions in 7- and 8-year-old children in northern Sweden: prevalence rates and risk factor pattern. Respir Med 1998;92:316-24.

25. Withers NJ, Low L, Holgate ST, Clough JB. The natural history of respiratory symptoms in a cohort of adolescents. Am J Respir Crit Care Med 1998;158:352-7.

26. Castro-Rodríguez JA, Holberg CJ, Wright AL, et al. Association of radiologically ascertained pneumonia before age $3 \mathrm{yr}$ with asthma-like symptoms and pulmonary function during childhood: A prospective study. Am J Respir Crit Care Med 1999;159:1891-7.

27. Dales RE, Zwanenburg H, Burnett R, Franklin CA. Respiratory health effects of home dampness and molds among Canadian children. Am J Epidemiol 1991;134:196-203.

28. Hopkin JM. Mechanisms of enhanced prevalence of asthma and atopy in developed countries. Curr Opin Immunol 1997;9:788-92.

29. von Mutius E, Martinez FD, Fritzsch C, Nicolai T, Reitmeir P, Thiemann H-H. Skin test reactivity and number of siblings. BMJ 1994;308:692-5.

30. Wickens KL, Crane J, Kemp TJ, et al. Family size, infections, and asthma prevalence in New Zealand children. Epidemiology 1999;10:699-705.

31. Björkstén B. The environmental influence on childhood asthma. Allergy 1999;54(Suppl 49):17-23.

32. Agabiti N, Mallone S, Forastiere F, et al, for the SIDRIA Collaborative Group. The impact of parental smoking on asthma and wheezing. Epidemiology 1999;10:692-8. 


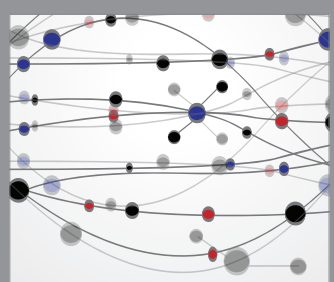

The Scientific World Journal
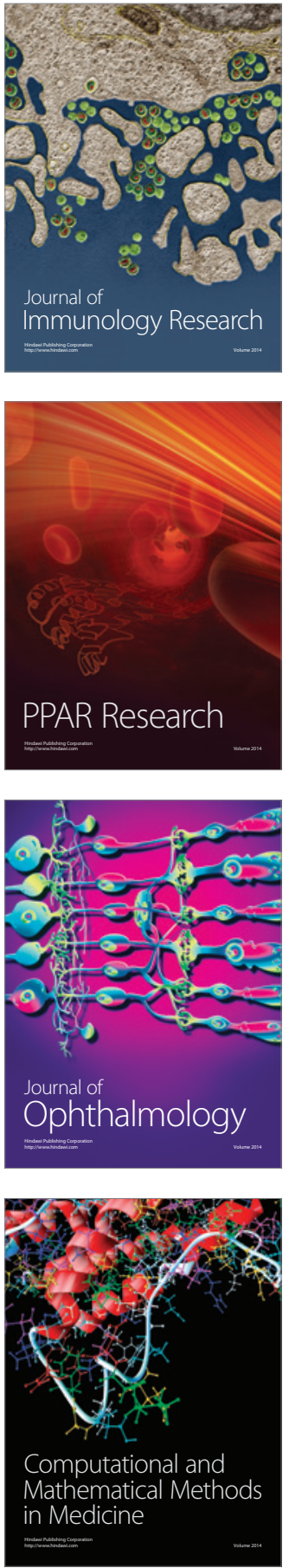

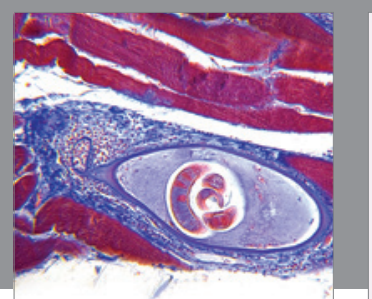

Gastroenterology Research and Practice

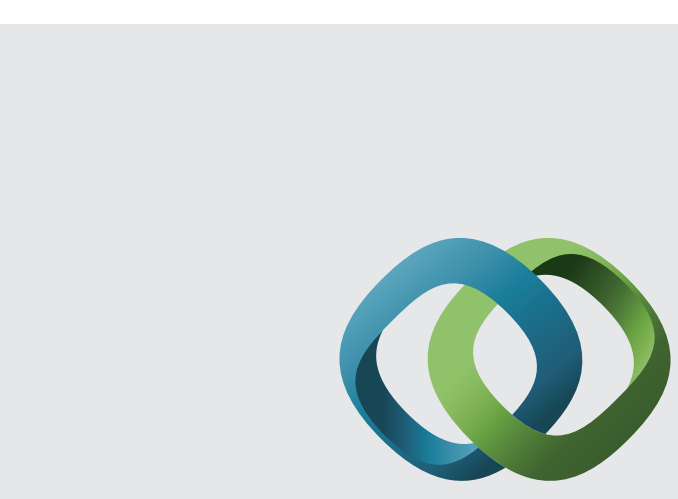

\section{Hindawi}

Submit your manuscripts at

http://www.hindawi.com
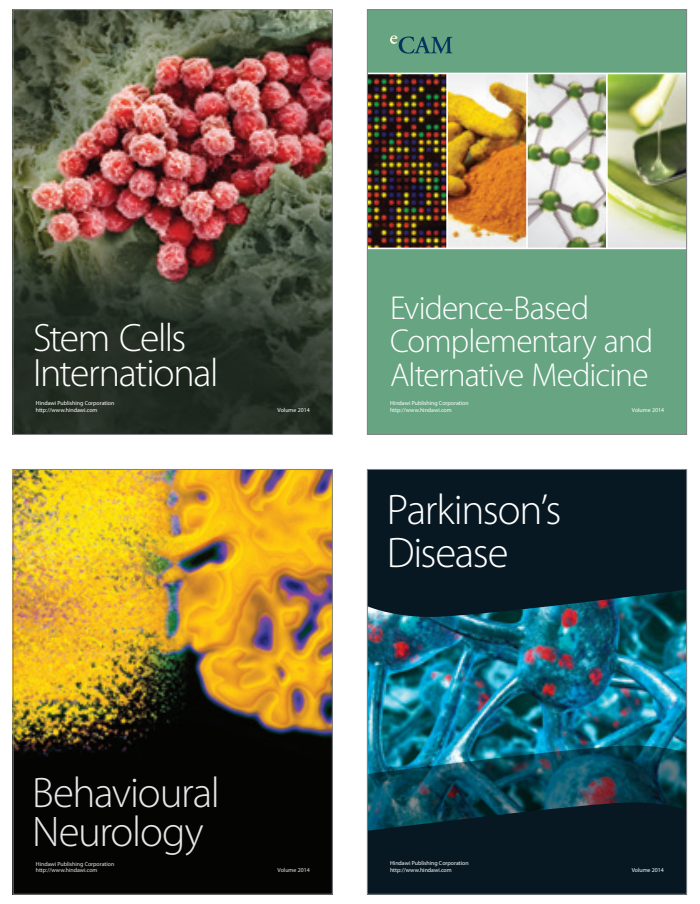
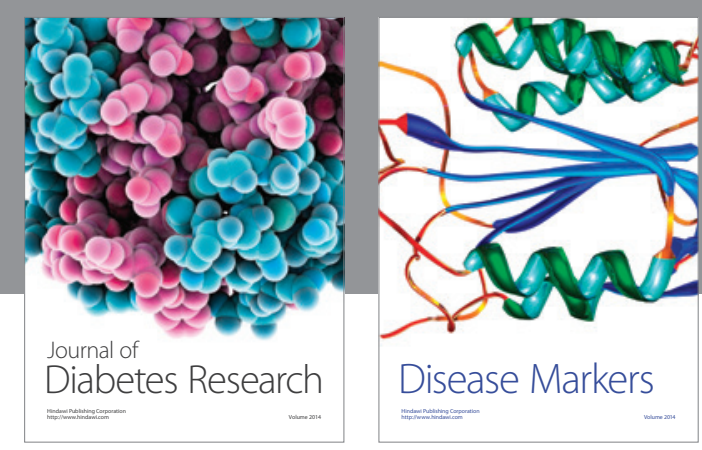

Disease Markers
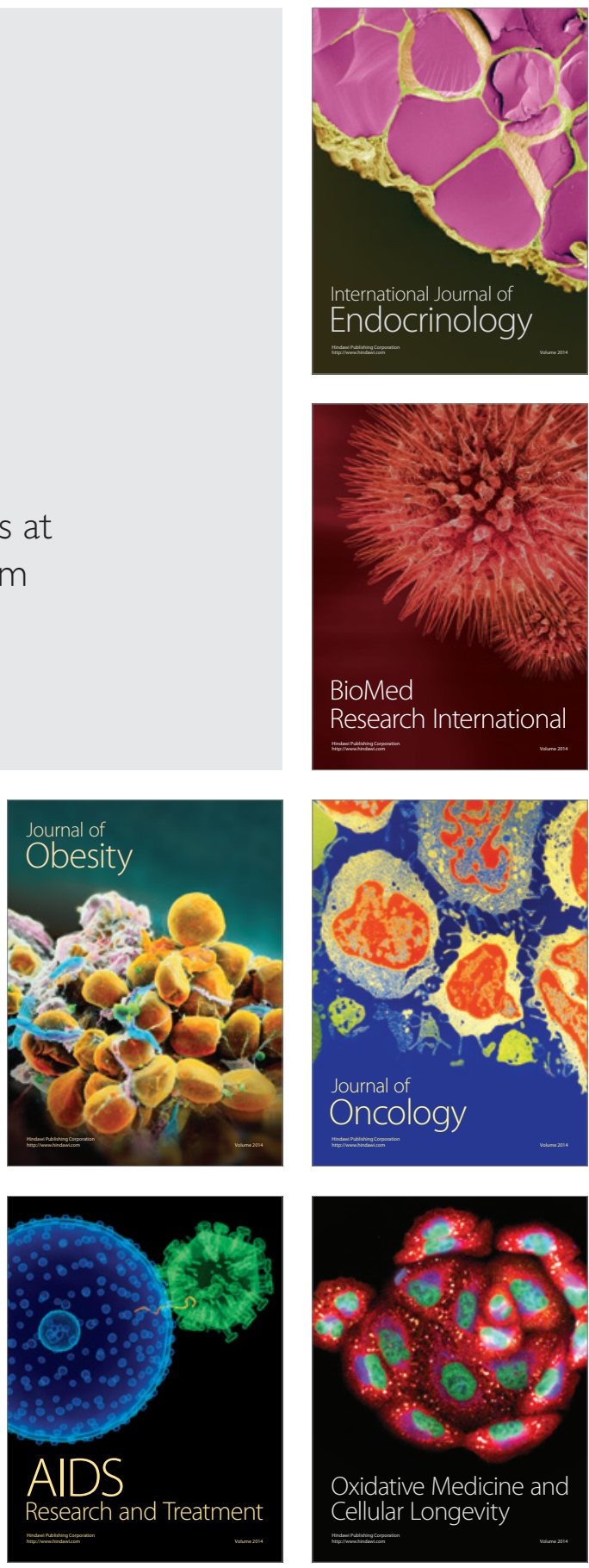